\title{
La escuela y el niño como víctima del conflicto armado en Tumaco, Colombia ${ }^{1}$
}

\section{School and children as victims of the armed conflict in Tumaco, Colombia}

\author{
Stella Rocío Ramírez Villegas ${ }^{2}$ \\ Universidad San Buenaventura \\ (iD) https://orcid.org/0000-0001-7012-6870
}

\section{Sandra Liliana Londoño Calero ${ }^{3}$ Pontificia universidad Javeriana Cali \\ (iD) https://orcid.org/0000-0002-9130-7504}

\begin{abstract}
Resumen: El presente artículo tiene como objetivo visibilizar las voces de algunos actores de la comunidad educativa de dos instituciones públicas de Tumaco: la General Santander y la Roberto Mario Bischoff, para mostrar cómo la escuela enfrenta el desafío de sumar a su tarea de educar, la de resolver los impactos de la violencia. Se reflexiona en particular sobre el niño y la niña víctimas, cuyo origen en el tiempo devela la construcción de la nación colombiana como un proyecto inconcluso de modernidad. En el origen del conflicto armado, resistir a la modernización ha sido convertirse en el diferente, en "el otro", en el enemigo. Se ilustra con algunos fragmentos recogidos de entrevistas abiertas y semiestructuradas como parte de un proceso de investigación acción-participativa, las vivencias de la comunidad educativa en medio del conflicto y la propuesta a través de la cual las escuelas en mención han enfrentado un nuevo rol, fundamentadas en la teoría crítica de la esperanza. Las escuelas han asumido reconstruir saberes, pedagogías y lineamientos institucionales, para ganar el pulso a la violencia, que viene de la mano de actores armados que crean al niño y la niña víctima, los alejan del sistema educativo y los incluyen en un conflicto que les es ajeno. Esta es la historia del esfuerzo de dos instituciones educativas por asumir con mejores elementos la finalidad de reducir los efectos de la violencia como una tarea que excede la competencia de la escuela, pero que no puede ser ignorada por ella.
\end{abstract}

Palabras claves: conflicto social; escuela; niñez; víctima de guerra.

Recibido: 15/07/2019| Aceptado: 17/07/2020| Disponible en línea: 30/07/2020

Como citar este artículo: Ramírez, S. R. y Londoño, S. L. (2019). La escuela y el niño como víctima en Tumaco, Colombia. Jangwa Pana 19(2), 245 - 260. Doi: https://doi.org/10.21676/16574923.3610

Abstract: This article aims to make visible the voices of some actors in the educational community of two public institutions in Tumaco, General Santander and Roberto Mario Bischoff, to show how the school deals with the challenge of adding to its task of educating, that of resolving the impacts of violence. It reflects in particular on

\footnotetext{
${ }^{1}$ Este artículo se presenta como resultado de la investigación doctoral denominada "Lineamientos para una propuesta educativa crítica para escuelas en contexto de conflicto armado en Tumaco-Nariño". Las autoras se reconocen independientes de las instituciones financiadoras del proyecto y con autonomía para presentar los resultados expuestos en el presente artículo como muestra del ejercicio investigativo.

${ }^{2}$ Correo electrónico: sterorav@yahoo.com

${ }^{3}$ Correo electrónico: sandra.londono@javerianacali.edu.co
} 
the boy and girl victims whose origin in time reveals the construction of the Colombian nation as an unfinished project of modernity. At the origin of the armed conflict, to resist modernization has been to become the different, the 'other', the enemy. It is illustrated with some fragments collected from open and semi-structured interviews as part of a process of Participatory Action Research, the experiences of the educational community in the middle of the conflict and the proposal through which the mentioned schools have faced a new role, based on the critical theory of hope. The schools have assumed the reconstruction of knowledge, pedagogies, and institutional guidelines, to win the pulse of violence, which comes from the hand of armed actors who create the victim boy and girl, push them away from the educational system, and include them in a conflict that it is alien. This is the story of the effort of two educational institutions to assume with better elements the task of reducing the effects of violence as a task that is beyond the competence of the school, but that cannot be ignored by it.

Key words: war victim; school; childhood; social conflict.

\section{Introducción}

Las historias del trauma vivido por la guerra y el conflicto armado en Colombia tienen a niños y niñas como protagonistas. Estas narrativas forman parte de la cotidianidad de Tumaco, en Nariño, Colombia, una de las regiones con más presencia de actores armados y, por tanto, de violencia, desde finales de la década de los noventa en el país (Duarte, y otros, 2020). Lo que se presenta en este artículo es parte de una investigación más amplia cuyo objetivo general fue proponer algunos lineamientos para la transformación de los currículos escolares con el fin de mitigar los efectos de la violencia en escuelas convencionales para estudiantes sometidos a grandes presiones por los grupos armados en el territorio. En este documento se da cuenta de una parte de esta pesquisa; en particular, se trata aquí de visibilizar algunos de los efectos directos de la violencia sociopolítica, reflejada en niños y niñas en edad escolar dentro de procesos educativos en currículos oficiales y cómo los enfrentaron dos instituciones educativas de la ciudad. Para hacerlo se muestran algunas de las historias recogidas en el proceso que revelan la problemática, y que sirvieron de base para articular los lineamientos que solo se esbozan en este texto, y que apoyan la tarea educativa de dos escuelas elegidas en Tumaco.

A medida que se despliegan los fragmentos de historias que se eligieron como ejemplos, se toma postura sobre la manera en que el conflicto armado en Colombia crea víctimas; las crea porque, como se argumenta más adelante, pone en contraposición actores que esencialmente no tenían disputa o que estaban fuera de ella, pero que las condiciones sociales, políticas, culturales los llevan a la confrontación. El niño y la niña son captados por los grupos armados y son subordinados a una lucha que no les corresponde; son botines de guerra, sujetos víctimas o combatientes de una confrontación atávica cuyos orígenes están sepultados en el tiempo y que Colombia no ha logrado superar. La escuela se constituye como el lugar de paso de estos niños y niñas, y durante el lapso en que los tiene consigo trata de contenerlos para evitar la deserción, el mal desempeño y las largas ausencias, factores que muestran el involucramiento de los estudiantes en el conflicto, y que algunas veces llevan a la delincuencia, la drogadicción y la ilegalidad.

Para conceptualizar y profundizar este supuesto que se constituye en el objetivo de esta parte de la investigación, aquí reportada, primero se hablará del sujeto víctima, para lo cual se busca comprender, desde una nueva manera, la expresión invención del otro, precisada en 
los trabajos académicos de Castro-Gómez (2000) y González-Stephan (1994) sobre los procesos de modernización en Latinoamérica. Esta perspectiva de la colonialidad puede encontrarse también en los trabajos de los autores del giro decolonial, que igualmente reconocen que América Latina fue desplazada de la modernidad, y por ello se "esforzó" por alcanzar a los que pudieron ingresar en ella, los mismos cuya matriz los colonizó históricamente (Walsh, 2003), una matriz violenta y arrasadora de cualquier identidad diversa, que fracturó sus comunidades y dislocó sus identidades. Esto en Colombia fue un proceso profundo y devastador.

El "otro", representado en el opuesto o resistente a la modernidad, se instaló probablemente como enemigo, y el enemigo, cuando está en resistencia, solo puede ser persuadido por la fuerza. A pesar de que la colonización ocurrió como un hecho en América hace mucho tiempo, la polarización que posiciona a grupos humanos en orillas opuestas se mantiene y recrea en la violencia que hasta el presente se vive en Colombia y en otros países de muchas y muy diversas maneras (pobreza, exclusión, racismo, violencia).

Los proyectos de Estado-nación modernos vinieron con la propuesta de alfabetización que propagaron las primeras misiones educativas en América, y de manera violenta, por grupos armados y liderazgos políticos de élite. La idea de "la letra con sangre" permitió forjar al ciudadano homogéneo capaz de formar parte de una misma nación, que declinó su identidad por los ideales de una cultura moderna y desarrollada que otros le impusieron (Duarte, 2018). No obstante, no lograron persuadir a todos ni doblegarlos. La perspectiva del ciudadano "inventado" por el poder muestra para un país como Colombia desde la segunda mitad del siglo anterior la degradación de un proyecto inconcluso: un proyecto de modernización que quedó a medias.

Este proyecto fracasó al quedarse detenido en un conflicto virulento de fuerzas en pugna (guerrilla-paramilitares/Estado) que nadie ganó y que sin triunfadores reales dio paso a diversos acuerdos de paz en la historia del país. El más reciente tardó más de cinco años en concretarse, primero con el proceso de negociaciones en La Habana-Cuba hasta la firma del acuerdo final en Bogotá un año después. Lo que quedó en evidencia es que el Estado colombiano no logró doblegar a los grupos insurgentes ni estos lograron la victoria según sus ideales. Las luchas entre bandos y posiciones fueron dejando miles y miles de víctimas que tuvieron que vivir la guerra y el paulatino surgimiento de nuevos grupos sustentados, por un lado, en las economías ilegales del narcotráfico, y, por el otro, en la venganza de muertos de cada bando en territorios que acumularon violencias (FIP, USAID, OIM, 2014). En este contexto no se alude solo a la violencia directa perpetrada por grupos armados, sino también a la estructural de la pobreza y la marginalidad, ejercida por el Estado, y a la cultural o simbólica del racismo y la exclusión, tal como lo señala Galtung (2016) en su ya famoso triángulo de la violencia. El proyecto de nación moderna inicialmente justificó los actos violentos que perpetró por su esfuerzo en el logro de una sociedad homogénea y equilibrada, pero no fue más que el vehículo de la polarización y el conflicto que aún subsiste y se hace más violento en las zonas rurales y con presencia étnica, como Tumaco.

El punto que se sostiene en este artículo es que la imposición de ese ciudadano desarrollado no pudo canalizarse solo por las instituciones sociales convencionales como la escuela, y que incluso la escuela misma fue un vehículo de violencia al imponer el proyecto del colonizador. 
La fuerza para lograr los ideales de la nación alcanzó niveles de degradación inimaginables en Colombia. Despojó de tierras y derechos a algunos y sigue cobrando vidas en el presente. El relato de un excombatiente citado por Moreno (2012, p. 578) ejemplifica cómo la guerra y su aparato de actos y discursos dislocó para los combatientes la noción del "otro": "Es triste saber que la guerra fue muy dura allá y saber que la guerra lo convierte a uno en criminal". La guerra, despojada de su investidura ideológica, revela al final de los días para el sujeto combatiente la degradación moral de muchas de sus acciones. Lo que queda al descubierto es que las operaciones contra el "enemigo" no fueron tal vez más que crímenes a secas y no necesariamente actos heroicos.

El proceso de construcción de la nación colombiana, tal como se argumenta aquí, se configuró como la sistemática obliteración de la población civil, como un conflicto que transformó, especialmente al sujeto rural y étnico de las regiones apartadas del centro, en enemigo histórico con una deuda que heredan sus descendientes o que llevan como estigma familiar. Por eso también alcanza a los niños y niñas, no importa su edad o condición (Salgado, 2012). Estas marcas en las niñas y niños justifican la aniquilación, el sometimiento y la vulneración despiadada, utilizando todos los medios violentos a disposición. Algunos ejemplos de esta violencia se reflejan en el reclutamiento forzado de niñas y niños, a quienes raptan de las familias y de las escuelas en los territorios, y en las violaciones de mujeres, para desmoralizar a los opositores y evitar el liderazgo femenino. Todos estos actos se sustentan en ideales de Estado y de nación; una patria libre del "otro" que es considerado estorbo, opositor, diferente, enemigo; un "otro" que a veces no es un combatiente, sino un civil, una niña o un niño que en su vulnerabilidad frente a las fuerzas en pugna tienen pocas opciones para defenderse y resistir.

Los discursos sobre el conflicto entre el Estado y los combatientes son uno de los tantos "campos de batalla" donde queda atrapado el sujeto-enemigo (Angarita Cañas, Gallo, Jiménez, Londoño Berrío y Londoño Usma, 2015), el sujeto que debe ser destruido o utilizado como medio para destruir a otro, con el fin de neutralizarlo y devastarlo moralmente. Ese sujeto-enemigo es un "muñeco", de hecho, así se suele hablar de él cuando está muerto o cuando está próximo a ser asesinado. Está despojado de su identidad, de sus sentimientos, de sus valores y de sus ideas. Está más bien investido de razones para perecer (es informante, es del "otro" bando, es colaborador o no colaborador, es combatiente, es lo más querido del enemigo, o es simplemente víctima). El perpetrador, por su parte, se desvitaliza, se exime, se justifica (solo cumple órdenes, tiene razones de venganza, debe ser persuasivo, actúa en defensa, recupera lo que ha perdido, es soldado, es militante, o cualquier otro epíteto de similares características) (Salamanca, 2007)

En estos espacios que comparten ciudadanos y grupos armados en medio del conflicto interno coexisten dos espacios semióticos: el de la víctima y el del poder (Mignolo, 1978). Quienes se arrogan el poder, justifican sus acciones y pueden hablar; a ellos corresponden las razones, los códigos y las órdenes; la víctima por su parte solo puede ser nombrada por otros; la víctima no tiene poder, está presionada a callar y a aceptar ofendida y en silencio todo lo que sobre ella se cierne para preservar su vida o la de sus seres queridos. Cuando habla en su nombre, corre peligro de muerte, cuando resiste es amenazada, si no acepta su condición de 
víctima, pierde toda ayuda y queda vulnerable. Es el "exilio interno" del que habla Molano (2003), aceptado por la víctima para defender su vida.

A la escuela precaria y precarizada, por la falta de recursos y apoyo, se le encarga recibir a ese sujeto víctima, algunas veces incluso con el doble rol de víctima y victimario (niño víctima-combatiente, niño víctima obligado a consumir y a trabajar en el cultivo de la coca). La escuela debe ser la alternativa, debe mitigar, reconducir, ser y presentar alternativas para la pobreza, el reclutamiento infantil, la marginalidad, el trauma de guerra, la exclusión social, el desempleo, el mal uso del tiempo libre, el desplazamiento forzado, el tráfico de drogas y el consumo y otros tantos productos del conflicto social, político, económico y cultural que afecta a las zonas más pobres del país. A la escuela se le encargan estos problemas y se les suman exigencias a sus currículos, porque debe recibir y mantener interesados a los niños y niñas del conflicto (Londoño, 2019). Las investigaciones del Servicio de Jesuitas a Refugiados muestran que donde hay escuela y donde los niños y niñas pueden todavía asistir para avanzar en sus estudios, hay menos efectos negativos para los más pequeños, y esto se capitaliza y se exige a la escuela. No obstante, la escuela en estas zonas no tiene todos los mecanismos para resolver la miríada de demandas por fuera de su competencia (Fernández Aller y De Luis, 2010); quizás ninguna escuela está hecha y preparada para esto.

Las instituciones educativas con su tarea de educar a los individuos del modo en que el sistema concibe al colombiano, debe reinventarse en un conflicto degradado que traspasa todos los límites discursivos del derecho internacional humanitario y de cualquier retórica protectora; parafraseando a Agamben (2006), la escuela despojada de todo lo sagrado no puede evitar que a su interior proceda la violencia. La infancia es despojada de sus significados, para que no quede finalmente más que el sujeto enemigo o el sujeto arma de la guerra, con solo valor de cambio como trofeo ante el enemigo. Sin el límite discursivo que proteja a la escuela, la infancia, el maestro, no tienen otras opciones más que resistir, sumarse a la guerra o desaparecer. De hecho, muchos niños no vuelven a la escuela, muchas escuelas desaparecen y muchos maestros corren suerte similar. Desprovistos de la escuela los niños y niñas del conflicto, los futuros ciudadanos víctimas se quedan sin un espacio alternativo para pensar otras identidades, otras luchas distintas en nuevos lugares.

Para 2011, en los países afectados por conflictos, Unesco registraba algunas cifras que permiten hacerse una idea de la magnitud de los efectos de la guerra sobre la infancia y sobre la escuela. De acuerdo con el informe Una crisis encubierta: conflictos armados y educación, el $28 \%$ de los niños y niñas en edad de cursar la primaria estaban sin escolarización, lo que representaba el $42 \%$ de niños del mundo privados de esta educación por razones de guerra. Los niños y niñas en países en conflicto tienen dos veces mayor probabilidad de fallecer que los niños y niñas en países pobres. En general, estas es una estadística preocupante para afrontar en el marco de un proyecto de escuela. De los niños y niñas escolarizados, gracias al déficit en calidad de la educación, las escuelas se convierten en sí mismas en factores de riesgo del conflicto. Se añade a todo ello la violación del Derecho Internacional Humanitario que ha permitido que niños y maestros sean blancos legítimos de la guerra y que los muros de la escuela no los protejan nunca más (Unesco, 2011).

Hace seis años, en el 2014, en el corregimiento Chilví a 20 minutos de Tumaco, dos niños de trece y catorce años fueron usados por la guerrilla de las FARC para lanzar 
unas granadas de fragmentación en una cancha de fútbol donde policías jugaban informalmente con una pelota, como desenlace, los dos niños murieron (Semana, 5 de mayo de 2014).

Esta estrategia no era única ni mucho menos nueva, ya se conocía en el país el caso de Heriberto Grueso, un niño de 12 años que voló en pedazos cuando su maestra le dio permiso en el recreo para ir con su hermanito menor a buscar algo de comer a su casa. El niño que apenas cursaba tercero de primaria fue engañado; con la ilusión de recibir 1000 pesos por hacer un favor, explotó con diez kilos de anfo que pusieron en su bolso escolar. Esto sucedió en el Charco, Nariño, población a 104 km de Tumaco (Semana, 4 de febrero de 2014).

En medio de una realidad tan abrumadora, la escuela que necesita asumir los roles que le impone estar en medio del conflicto puede mirar como opción la pedagogía de la esperanza. Esperanza como idea de futuro, opuesta al miedo, movilizada a la acción. Una esperanza activa, sin romanticismo, con fuerza y deliberación colectiva: esperanza como colaboración y solidaridad. "Sin la fuerza de un yo y de un nosotros detrás, la misma esperanza se hace vacía" (Bloch, 2007, p. 3). La esperanza debe ser consciente para que no se debilite y penetre la voluntad. Con el miedo que ejercen los violentos como mecanismo de dominio, la esperanza se fortalece y se torna activa, transformadora, emancipadora, no pasiva como el miedo mismo (Fromm, 1968; Freire, 1996; Bloch, 2007; De Sousa Santos, 2019). La pedagogía de la esperanza, como hija cercana de todos los esfuerzos liberadores en América Latina, se levanta como una opción de futuro. La esperanza es el camino al porvenir. A partir de ella se construyen actividades, contenidos, proyectos que movilizan la escuela. Este artículo muestra cómo la escuela puede asumir la esperanza para conjurar el miedo, como respuesta a la imposibilidad de quedarse cruzado de brazos, inerme, fortaleciendo y creando a la víctima que ya nada puede hacer.

\section{Metodología}

El trabajo que se presenta aquí se realizó con base en la recuperación de relatos por medio de entrevistas. Estas son parte de un proceso más amplio de investigación acción-participativa (IAP). Desde una perspectiva fenomenológica, la entrevista se considera una experiencia de creación de significados entre sujetos que establecen un diálogo, una conversación con un propósito que es en sí mismo una manera de entender, de resignificar, de dar sentido a una realidad que se vive y que se necesita comprender (Kvale y Brinkmann, 2009). Por esa razón no solo es subsidiaria de la IAP o un mero instrumento o herramienta de investigación, sino también una forma de investigar. Se realizaron entrevistas abiertas y semiestructuradas que recogieron vivencias del día a día de los actores educativos. En este artículo se presentan siete fragmentos de relatos que recuperan experiencias relacionadas con la identificación de la niña y el niño como sujetos víctimas creados por el contexto de violencia social y política en Tumaco, que son ilustrativos del supuesto sobre la creación del niño y la niña víctima, y de las situaciones que enfrenta la escuela para sobrellevar la tarea de transformarlos, y de este modo puedan vivir una existencia alejada de esta matriz que los determina y marca su futuro, las más de las veces de forma muy negativa. 
Los fragmentos provienen de entrevistas realizadas a miembros de la comunidad educativa de dos instituciones públicas en la zona urbana de Tumaco, Nariño, en Colombia: la institución educativa General Santander y la institución educativa Roberto Mario Bischoff (R. M. Bischoff), ubicados en zona marginal del casco urbano de Tumaco, donde habita población que sobrevive de la pesca artesanal. La zona en la que se ubican las IES enfrenta la acción permanente de grupos armados que ejercen el control total de los barrios.

Los fragmentos escogidos se recogieron de las experiencias narradas en entrevistas durante el proceso investigativo, por maestros, padres, estudiantes y administrativos de las IES, que forman parte del programa de aceleración del aprendizaje. Dicho programa trabaja con niños y niñas que han pasado la edad promedio para estar en algunos grados porque han vivido situaciones relacionadas con el conflicto armado (reclutamiento, victimización) y/o la violencia intrafamiliar, hecho que ha afectado su permanencia regular en la educación formal y su rendimiento escolar.

Los fragmentos elegidos tomaron en consideración el supuesto del sujeto víctima creado por el conflicto que se ha venido presentando a lo largo de este texto. En ellos se analiza cómo la violencia ejercida sobre ellos y sus familias transformó sus vidas y legó a la escuela el papel de contenedor que se acomoda o ajusta a las situaciones de las niñas y de los niños. De este modo se extendieron las funciones para las cuales fueron creadas las escuelas, es decir: se les exige algo más que educar y formar, para contribuir a contener a los niños y las niñas, apoyarlos y evitar que se vuelvan perpetradores o víctimas en el conflicto armado. Las IES no son solo las instancias de socialización y de formación a partir de los currículos oficiales, sino también las garantes de la salud y el bienestar que los menores no tienen en el resto de los espacios vitales.

Para realizar este trabajo se tuvieron en cuenta cuidados éticos, en particular el consentimiento y el asentimiento informado de los cuidadores o tutores y de las niñas y de los niños. Se actuó en todo momento mediante la consideración del principio de beneficencia y no maleficencia. Esto implica que no se realizaron entrevistas que pudieran poner en riesgo o que aumentaran la vulnerabilidad de las niñas y de los niños. Muchos de estos testimonios fueron parte de entrevistas en el marco del día a día de la escuela, justamente en el esfuerzo de contención que hacen las instituciones educativas a través de las maestras y de los maestros y demás autoridades de las instituciones educativas, y que luego son narradas por estos actores educativos como parte de las vivencias y experiencias de contención que deben hacer a diario en su trabajo. Estas vivencias fueron integradas al proceso investigativo, teniendo en cuenta un enfoque cualitativo en el que la participación del investigador en la realidad que indaga le permite reflexionar las vivencias, lo cual lo lleva a comprender a profundidad su significado. El trabajo contó con el acompañamiento de una psicorientadora que formó parte de la investigación y estuvo atenta a los participantes. Los nombres de las personas que compartieron sus testimonios se mantienen en reserva tomando en consideración su vulnerabilidad. Dentro del artículo se llama a las personas con otros nombres y se cita con el número de la entrevista para evitar su identificación.

El análisis de los datos se realizó con etiquetas basadas en conceptos iniciales del marco teórico, luego se identificaron constantes en los relatos y entrevistas que se constituyeron en categorías de análisis. La riqueza de distintas entrevistas, en las que los hallazgos se hicieron 
similares, permitió hacer triangulación de estos para entender el fenómeno de manera más amplia y profunda, aumentando la validez y la confiabilidad de los resultados cualitativos.

Como parte del proceso investigativo, se realizaron talleres y espacios de trabajo pedagógico que les permitieron a las dos instituciones educativas participantes continuar la conversación con sus profesores, estudiantes y directivos sobre la comprensión de su realidad y sobre los desafíos que enfrentan para mantener y contener a sus niños y niñas en medio del conflicto. Fruto de esta experiencia se construyeron algunos lineamientos que aquí se dejan esbozados, solamente para dar lugar al supuesto principal de este artículo alrededor del lugar del niño y de la niña como víctimas creadas por el conflicto armado y violento en el país, y en particular en Tumaco. A continuación, en la tabla 1 se exponen las categorías usadas para la reflexión en este artículo, que ayudan a orientarse en la presentación de los resultados.

Tabla 1

Categorías de análisis

\begin{tabular}{|l|l|}
\hline \multicolumn{1}{|c|}{ Categorías } & \multicolumn{1}{c|}{ Concepto } \\
\hline $\begin{array}{l}\text { Conflicto armado, vida cotidiana y y } \\
\text { escuela }\end{array}$ & $\begin{array}{l}\text { Narrativas levantadas en situación de entrevista que } \\
\text { ilustran sobre el modo en que el conflicto armado y la } \\
\text { violencia tienen representación en la vida cotidiana de } \\
\text { la escuela. }\end{array}$ \\
\hline El sujeto víctima & $\begin{array}{l}\text { Narrativas de sus experiencias de vida en las que } \\
\text { se refieren hechos y situaciones donde la niña o } \\
\text { el niño ha sido víctima del conflicto armado. }\end{array}$ \\
\hline $\begin{array}{l}\text { Las escuelas conteniendo o creando a } \\
\text { la víctima }\end{array}$ & $\begin{array}{l}\text { Informaciones obtenidas en entrevistas que } \\
\text { muestran los esfuerzos de la escuela para apoyar, } \\
\text { acompañar y evitar que las niñas y los niños } \\
\text { abandonen el sistema educativo. }\end{array}$ \\
\hline Lineamientos educativos & $\begin{array}{l}\text { Elaboración colectiva con la comunidad } \\
\text { educativa, producto de la reflexión en las } \\
\text { diferentes etapas de la investigación. Se } \\
\text { considera como la fase de devolución según la } \\
\text { metodología IAP. }\end{array}$ \\
\hline
\end{tabular}

Fuente: elaboración propia

\section{Resultados}

Este apartado de resultados se articula alrededor de las cuatro categorías mencionadas anteriormente: conflicto armado, vida cotidiana y escuela, el sujeto víctima en Colombia como "invención del otro", las escuelas conteniendo las víctimas, y lineamientos curriculares. 


\section{Conflicto armado, vida cotidiana y escuela}

El relato a continuación ha sido traído de una historia contada por la rectora de uno de los colegios que formaron parte de la investigación, a partir del acompañamiento que hizo a uno de los niños de su institución, reportado como distraído y aislado en el aula por sus maestros. Se trata de exponer a través de este relato el tipo de situaciones que se enfrentan a diario en la escuela, que muestran la gravedad de las situaciones vividas, y que por tanto exigen a la escuela contención y apoyo.

Esteban de ocho años dejó de usar el lado izquierdo de su cuerpo. Era un día lluvioso cuando se vio llegar a Tumaco un grupo de paramilitares. La gente hablaba de las Autodefensas, pero como nadie había visto nunca una ejecución pensaron que era solo una amenaza. Sacaron a Alcides de su casa acusándolo de ser un informante del Ejército. A alguien se debía culpar por difundir que en los alrededores se cultivaba coca. Los vecinos de la localidad lo acompañaron atado a un madero en el parque durante toda la jornada sin poder hacer nada y, al caer la tarde, Esteban vio rodar la cabeza del hombre como consecuencia de una ráfaga de disparos. Esta fue quizás la experiencia más impactante de su corta vida. Días después el niño perdió la movilidad de su lado izquierdo y casi no hablaba. En este estado fue enviado a la escuela, que no sabía en realidad cómo ayudarlo; todos dicen que Esteban quedó silencioso y rígido después de presenciar aquella ejecución y encontrarse de frente con un desconocido que llevaba uniforme militar. (E1, 2015).

La escuela vive una profunda crisis social y política. A su tarea tradicional de formar a través de grados sucesivos a la persona, se le ha pedido dar prioridad a una nueva labor, la de ser albergue protector de las niñas y de los niños. El conflicto armado ha permeado todos los estamentos de la sociedad en Tumaco, y en estos la escuela no ha sido la excepción. Ha afectado el proceso educativo y la vida cotidiana. El miedo es el dueño de la situación y la inseguridad es una constante. No hay continuidad en las clases. Los niños, niñas y jóvenes prefieren delinquir a estudiar. Consumen estupefacientes desde muy temprana edad y resulta un desafío afrontar su desinterés por estudiar.

He atendido casos de consumo en adolescentes escolares, que en una encuesta que apliqué me permitió comprobar que, de 10 estudiantes, 7 habían consumido alguna sustancia alucinógena y 4 de ellos se habían quedado en el consumo. (E2, 2015).

La escuela perdió autoridad y autonomía. Los horarios y cronogramas escolares están afectados por las órdenes de grupos al margen de la ley, radicados en los barrios aledaños a las instituciones. Estos grupos dictaminan horas de ingreso y de egreso. En los tiempos de cosecha de la hoja de coca, algunos padres y madres se llevan a sus hijos para realizar la tarea, lo cual tiene como consecuencia que las niñas y los niños abandonen los estudios por determinados periodos, $\mathrm{y}$ a veces en forma definitiva.

En Tumaco, el posacuerdo no trajo consigo el cese de hostilidades. Por el contrario, logró que llegaran al territorio otros grupos que disputaron con los ya establecidos los espacios que ocupaban las FARC. Esta situación agudizó aún más el conflicto armado, dejando muertos 
en distintas partes de la ciudad. Testimonio de ello lo dan niños, niñas y jóvenes, y en general los y las ciudadanas que observan con silencio e impotencia su propia situación.

Hablar de posconflicto... [silencio], en Tumaco no ha cesado el conflicto, se ha agudizado. Hay zonas donde los maestros no quieren ir por la inseguridad, Alto Mira (vereda del Municipio de Tumaco) quedó desamparado. Hay zonas donde los mismos padres y madres de familia les inculcan a los hijos e hijas trabajar, toda la familia se dedica a la cosecha de hoja de coca. Los chicos empiezan a tener dinero, jóvenes entre los 12 y 13 años ya se ven en prostíbulos, gastando el dinero obtenido... licor, mujeres. $(\mathrm{E} 3,2015)$.

\section{El sujeto víctima en Colombia como "invención del otro"}

Al sujeto víctima solo le basta el discurso que lo representa, que lo crea y recrea. Es fruto de las narrativas institucionales, periodísticas o de los intelectuales que reflexionan la violencia. La víctima no habla, calla y se retrae para sobrevivir. Un testimonio sobre la muerte de uno de los chicos de una institución educativa y de su madre en Tumaco perpetrado por un grupo guerrillero ilustra este punto del silencio de la víctima y del costo de empoderarse o apoderarse de la palabra:

Lo que pasa es que Concepción entregó al ejército a uno de los hijos mayores porque no estaba de acuerdo con lo que hacía. Concepción no podía quedarse callada y simplemente trabajar en su local como todos los días. Se dice que uno de sus hijos formaba parte de uno de los grupos subversivos, y que el otro hijo estaba en el bando contrario. Cuando la fiscalía y los organismos de protección del Estado lo recibieron, se supo que había "cantado". A partir de ello quedó sentenciada la muerte del joven que se entregó y de toda su familia. Inclusive quedó marcado el más pequeño que para entonces cursaba la primaria. Concepción y el menor de sus tres hijos murieron asesinados en su casa mientras descansaban. Ella había dicho que no iba a salir corriendo con miedo y que no se iba a quedar callada. Pese a que le advirtieron que debía irse. Concepción no quiso hacerlo. (E4, 2015).

Concepción se atrevió a hablar, a hacer lo que creía correcto y se resistió a correr y a callar. No aceptó su condición de víctima: esa construcción que otros habían hecho de ella y su familia que la condenaban al desplazamiento y al silencio. El Estado protegió a aquel que ella entregó (al combatiente reinsertado), pero no a su familia, no a su madre que se atrevió a hablar ni al más pequeño de sus hijos que siguió asistiendo a la escuela, para dejar a los pocos días en estupor a toda la comunidad educativa. El pequeño no volvió asumiendo en la muerte su desde siempre estigma de víctima.

\section{Las escuelas conteniendo o creando a la víctima}

La violencia en Tumaco es una realidad cotidiana. La escuela de una zona de conflicto se reconfigura todos los días, bien porque se sobrevivió un día más a un evento violento o bien porque se ajustó a condiciones cambiantes en medio del conflicto: un grupo de nuevos 
alumnos, los que llegan desplazados, los que son captados por los grupos ilegales, los que no pueden volver a clase, los que expresan en el aula el miedo, los que mueren por la guerra y ya no regresan, o los ajustes que dictan los grupos ilegales mediante los cuales definen los horarios y modos de proceder en la escuela.

La escuela debe adaptarse y reinventarse porque no puede simplemente ignorar lo que se cierne sobre ella. Su tragedia es que no lo puede remediar porque la magnitud del conflicto excede todo aquello para lo cual fue creada. Asistir a la escuela no es la solución de todos los problemas sociales de esta zona del país, ni la acción de educar es la acción más potente que sobresale en la cotidianidad. Los actores ilegales suelen tener anzuelos, propuestas llamativ as, dinero, dejando a la institución educativa en desventaja. La escuela tiene el potencial de liberar al sujeto niño o niña y víctima del estigma de la guerra, pero en ocasiones no puede evitar contribuir a crear la víctima, a reforzar su identidad. Y es que el niño que se dice víctima, que cuenta su historia, que lleva su drama a la escuela, queda identificado, excluido o fuera de un sistema que no tiene los recursos para poderlo ayudar.

Las maestras, maestros y directivas asumen al niño y niña-víctima sin muchas herramientas. Hacen caso de las rutas y protocolos que el Estado les ofrece para trabajar con los niños y niñas. Tienen, en el mejor de los casos, psicólogos o psicorientadores que se preparan como pueden para atenderlos. Pero estos protocolos no dicen qué hacer cuando el niño no puede ser identificado como víctima, cuando la niña o el niño callan porque corre peligro su vida o porque puede ser estigmatizado o porque ya tiene un plan para abandonar la escuela y vincularse como combatiente.

Cuando la niña o el niño no dicen que son desplazados, no son ayudados ni comprendidos en su insuficiencia. Si dicen que son desplazados, o si presentan en sí mismo una condición que los delata como víctimas (golpes, lesiones físicas o psicológicas), puede ser más fuertemente castigado, puede ser foco de burlas y de una nueva marginación. Una segunda revictimización sucede y la escuela crea y recrea a la víctima nuevamente. El niño-víctima es sujeto de la caridad, de la conmiseración, del tratamiento y de la ley. El niño-víctima es todavía más obliterado que cualquiera, porque a su condición de menor de edad sobre el que otros deciden se suma la de vulnerado, la de víctima, un calificativo con el que la escuela aún no tiene claro qué hacer. Esto es más grave aún para el niño que es victimizado a través de la conversión en delincuente o combatiente, porque es seducido por el dinero, por las armas, por una vida que lo salva de la pobreza y otros tipos de violencia que padece en su hogar o entorno inmediato. Cuando esto sucede la escuela está más impotente aún. Tiene menos elementos para atraer al niño o niña que abandona el proceso.

La escuela en medio del conflicto trata de cumplir su labor de educar y se reinventa como puede para afrontar aquello para lo que no está preparada de asimilar ni contener. De institución normalizadora que reproduce el sistema social, y que en los resquicios intenta la emergencia de un sujeto que pueda pensar por sí mismo, debe transformarse en terapeuta, contenedora y alternativa para minimizar el impacto de todas las limitaciones sociales, políticas, económicas y de convivencia que el mismo sistema suscita. En el caso de la víctima, las funciones se multiplican al abrigo, al afecto, a la ayuda psicológica y a la contención de los efectos perversos de la guerra y la violencia a secas. 
Me encuentro con Katty de ocho años de edad que cursa segundo de primaria y fue testigo de un asesinato perpetrado en el barrio Humberto Manzi, en un sector denominado "Voladero" en Tumaco. La niña salía con su madre del barrio y se dirigía al colegio. Era aproximadamente la una de la tarde. Katty habla muy asustada. "Salió humo", dice la niña. "Vi a un señor en el suelo, me dio miedo" [...] Yo, la coordinadora de la escuela, no sé qué decirle, trato de distraerla con otra cosa, llevarla "al morro" [...] Ella me pregunta, pero trato de cambiarle el tema, de llevarla a otra parte. Katty dice: "andaban tras de nosotros, esos aviones que iban bajando". Yo sabía que se refería a los vuelos que realizan los helicópteros del batallón de infantería. (E5, 2015).

La escuela actual, pero en especial la escuela en una zona de conflicto debe asumir algo más que la tarea de lograr que los niños y niñas aprendan. Tiene la misión de contener y formar al nuevo ciudadano que ya fue hecho víctima, un sujeto creado en medio del conflicto armado, para que supere su condición o para que viva dentro de ella a fin de continuar en el circuito de ayuda del Estado. El niño-sujeto víctima es más vulnerable y silenciado que cualquier otro, más pensado por quienes encargados de él leen sus necesidades y toman decisiones en su nombre, pero es difícil hacerlo hablar sin tener cómo contenerlo.

Los maestros reciben a los chicos en la escuela, recuperando sus historias, conteniendo sus memorias y sus afectos deshechos y, como si no fuera suficiente sus tareas, reciben a los miembros de la comunidad educativa que miran hacia la escuela para saber qué hacer. No es extraño que ahora mismo en algún salón solitario testigo del llanto de algún niño, también se confiese un familiar, un tío, un padre de familia, al que la escuela debe contener.

Mi hermana Martina pasaba por la estación de policía, trayecto obligado para llegar a su sitio de trabajo y fue sorprendida por el estallido de dos cargas de pentolita. Confesaron los autores materiales de estos hechos que dejaron la carga un poco más allá porque temieron que los cogieran si se acercaban mucho a la estación de policía. Martina murió instantáneamente, no tenía nada que ver con el conflicto, su cuerpo quedó tirado en medio del desastre, mostrándonos a todos de lo que son capaces. Sé que mi sobrino sufre mucho, necesitaba a su madre demasiado. Me tocó asumir el rol de mamá e intentar llenar un vacío que jamás podré colmar en su totalidad... Todas las noches hablo con ella y le pido que me dé una señal. (E6, 2015).

El sujeto víctima es un sujeto creado como un "otro" que se despoja de su identidad y se vuelve estático, enemigo al que hay que aniquilar, o medio a través del cual se demuestra poder y se destruye moralmente a la contraparte. En Colombia, el sujeto-enemigo, como figura, ha atravesado todos los años que le ha tomado al país pactar un acuerdo. Hoy, que nadie ha podido ganar la contienda por las armas, se ha negociado reconociendo la degradación a la que llegó la disputa, y cómo, desprovista de su ideología, no resulta ser más que una miriada de crímenes a secas que exigen reconstruir memoria y garantizar reparación y no repetición. 


\section{Lineamientos educativos}

Del camino recorrido por dos instituciones convencionales en Tumaco, en conversaciones sobre la propia realidad y sus alternativas, surgieron propuestas movilizadas por la pedagogía de la esperanza en tres dimensiones. La primera se centra en los saberes (axiológicos, espirituales, emocionales, políticos, filosóficos) que permiten avanzar en el arte de construir colectivamente paz. La segunda se acerca a los lineamientos pedagógicos (la deliberación, el diálogo, el trabajo colectivo la investigación) que construyen y reconstruyen la palabra perdida y permiten hablar en primera persona. La tercera se refiere a los lineamientos institucionales (maestro orientador, familia como centro, emprendimiento y liderazgo para robar a los niños y niñas de las manos de los grupos ilegales, la recuperación de la identidad y la cultura como elementos protectores de lo comunitario). A esto se le llamará en las escuelas educar en la esperanza, o lo que en el proceso significa resiliencia, resistencia, memoria, reconciliación, pertinencia, provocación y proposición.

La esperanza es el camino, es el futuro que permite a la escuela asumir una tarea que la supera y la obliga a pensarse de otra manera. Así lo expresa una directiva académica en su apuesta de construcción colectiva en el escenario de las instituciones educativas seleccionadas.

"Me arrebataron a mi sobrino de la manera más cruel y despiadada, un joven de tan sólo 24 años, hijo único de mi hermana, una pérdida que ella llora y lamenta cada día, tratando de encontrar explicación y pidiendo valor al altísimo para no sucumbir. Me arrebataron a mi hermano mayor propinándole un disparo a quema ropa en la cabeza porque no tenía unos pocos pesos para darle para trago al integrante de un grupo que siembra el terror en mi pueblo".

Estas crueles experiencias son impulsadoras, también la esperanza franca y el deseo de contribuir y hacer que, desde el escenario educativo, se puedan generar algunos intentos por un mundo mejor, por hacer de la escuela un lugar para el perdón, la reconciliación, la memoria y el comienzo de una ilusión. Como rectora de un establecimiento educativo de Tumaco, ubicado en una comuna vulnerable, de gente con grandes afugias económicas y víctimas de grupos que se albergan en sus entrañas y que establecen las culturas del silencio y de la dominación, pero que aún sueñan con un futuro promisorio a pesar de las circunstancias, me mantiene de pie, el deseo de justicia, memoria y reparación como ejes de resiliencia. Cuando el conflicto armado toca tan de cerca el corazón, una tesis doctoral como esta se convierte en impulso recio de sacar el gran dolor que se alberga en el pecho, quemando las entrañas y la voz ahogada emerge con un grito de liberación. (Ramírez, 2020).

La escuela debe darles voz a los que han sido silenciados, a las víctimas de la violencia y, por qué no, a los victimarios. Ellos deben ser sujetos posicionados en su propia historia, no la deben contar organizaciones, ni personas externas a esa vivencia. Esto forma parte del ejercicio de la verdad como uno de los propósitos de la reparación integral, y en este sentido el currículo de la escuela debe apuntar a que no se conozca la historia contada por historiadores, sino por los sujetos que formaron parte de ella. 


\section{Discusión y conclusión}

La escuela queda investida y cargada de tantas propiedades, pero en sí misma es vulnerable y precaria, pues en las zonas de conflicto las escuelas reciben menos recursos, hay una presencia limitada del Estado y siempre se está bajo amenaza. Las escuelas que reciben a las víctimas no suelen saber, por fuera de los protocolos y de las rutas de atención, cómo contener o transformar su condición de víctimas.

Las instituciones educativas de Tumaco tratan de sobrevivir hoy, intentando superar cada evento, enseñando en medio de actos de barbarie y de violencia que ocasionan las ausencias de los niños y niñas el rezago escolar, la amplia deserción y los problemas de aprendizaje que en el caso de algunos niños no son más que un resultado obvio de la falta de condiciones materiales y emocionales en su vida, y de las limitaciones de la escuela para darle todo lo que necesita y que tampoco le corresponde solventar.

La escuela participa en la creación del niño-sujeto-víctima, sin duda, por su vulnerabilidad, por su falta de estrategias, por sus limitados recursos, por la enorme cantidad de funciones que se le cargan a la ya muy difícil labor de educar. La escuela, entonces, continúa paliando aquello que no es solo la violencia que desplaza o que asesina, sino que es la pobreza, el abandono, la injusticia, el racismo y el desequilibrio social.

De entre todos los resultados del conflicto, el sujeto-víctima es aquel al que se le ha negado toda voz; el que debe ser dicho por otros y el que debe resistir callado para vivir y para ser ayudado. Los niños y las niñas son en esta escena los más silenciados, pues por su madurez y por sus recursos están en situación de mayor vulnerabilidad.

Una sociedad sin recursos para afrontar la enorme cantidad de vicisitudes de la víctima pide a la escuela que contenga a la más vulnerable de todas ellas. Pide que evite que el niño sea reclutado y convertido en perpetrador, o que evite que sea revictimizado al negársele el derecho al futuro fuera de la escuela. Pero la escuela no fue creada para ello, y con dificultad soporta tantas tareas sumadas.

La escuela, no obstante, ya no puede defenderse ni a sí misma. Es ahora también una víctima, si esta categoría cabe a una institución social. Dejó de ser un espacio neutral, impenetrable y sagrado. La niñez dejó de ser defendida y el saber y el maestro perdieron el respeto que contenían las agresiones contra ella. En la degradación del conflicto, ninguna regla se sostiene en pie.

Queda mucho por decir a la escuela en tiempos de conflicto para procurar un espacio posible de reconstrucción de la educación en los siguientes años. El ciudadano víctima se forja con la convivencia a veces de la escuela cuando no tiene las condiciones de calidad para que el niño pueda pensar su futuro, pero aún sigue siendo, de entre los lugares, uno de los pocos reductos donde se puede revertir algo del efecto del conflicto mirando hacia el futuro.

Las instituciones públicas General Santander y Roberto Mario Bischoff en Tumaco asumen enfrentar su tarea imposible, a partir de lineamientos alrededor de los saberes, la pedagogía y el fortalecimiento institucional, orientados por la pedagogía de la esperanza de Freire 
(1966), por la revolución de la esperanza de Fromm (1968) y por la teoría de la esperanza crítica de Bloch (2016). Estas perspectivas orientan su labor para afrontar la misión educativa desde la resiliencia, la memoria, la reconciliación, la construcción de paz, con nuevos roles, con renovadas estrategias solidarias, colaborativas, que están del lado opuesto del miedo, que cultivan la esperanza y alientan la formación de la mente y el corazón. Maestros que esperan y no se derrotan, en medio de una situación que en mucho los supera.

Lejos de una solución, pero alentado por la esperanza, se sigue pensando el lugar de la escuela en el conflicto y en el escenario del acuerdo de paz. Todavía hay que filtrar de sus tareas aquellas que son capaz de asumir en propiedad además de la principal de educar. Habrá que pensar si le compete ser terapeuta, juez, refugio, médico, centro de memoria y otras tantas funciones que terminan bajo su responsabilidad. Está por pensarse su lugar en las condiciones del presente acuerdo y de los futuros.

El desafío para las instituciones educativas de Tumaco es muy grande, porque a su situación histórica en el conflicto se le suman condiciones de injusticia social muy severas. Esto queda como asignatura pendiente de esta investigación en desarrollo, que solo ha recogido hasta aquí los primeros testimonios y algunas ideas para el debate.

\section{Referencias}

Agamben, G. (2006). Homo sacer: el poder soberano y la nuda vida. Valencia: Pre-textos. Angarita Cañas, P. E., Gallo, H., Jiménez, B. I., Londoño Berrío y Londoño Usma, D. (2015). La construcción de enemigo en el conflicto armado colombiano 1998-2010. Medellín: Sílaba-Universidad de Antioquia-INER.

Bloch, E. (2007). El principio esperanza. Madrid: Trotta.

De Sousa Santos, B. (2019). Pedagogías de la educación popular. Diálogos entre lo ético y lo político. Cuarto Encuentro de Educación Popular. Bogotá: Universidad Pedagógica Nacional.

Duarte, C. (2018). Hacia una antropología del Estado colombiano: descentralización y gubernamentalidad multicultural. Cali: Sello Editorial Javeriano.

Duarte, C., Andrade, O., Castaño, A., Diaz, L., Giraldo, I., Lacoste, B., . . Trujillo, D. (2020). Pacífico en conflicto: Dinámicas históricas y territoriales de la guerra 1958-2016. Cali: GEUP.

Castro-Gómez, S. (2000). Ciencias sociales, violencia epistémica y el problema de la invención del otro. La colonialidad del saber: eurocentrismo y ciencias sociales. Perspectivas Latinoamericanas (pp. 145-161). Buenos Aires: Clacso.

E1. (2015). Relato Escuelas en Tumaco 1. (S. R. Ramírez, Entrevistador) Tumaco.

E2. (2015). Relato Escuelas en Tumaco 2. (S. R. Ramírez, Entrevistador)

E3. (2015). Relato Escuelas en Tumaco 3. (S. R. Ramírez, Entrevistador)

E4. (2015). Relato Escuelas en Tumaco 4. (S. R. Ramírez, Entrevistador)

E5. (2015). Relato Escuela en Tumaco 5. (S. R. Ramírez, Entrevistador)

E6. (2015). Relato escuela en Tumaco 6. (S. R. Ramírez, Entrevistador)

Fernández Aller, C. y De Luis, E. (2010). Educación. SJR. Madrid: Entreculturas.

FIP, USAID, OIM. (2014). Dinámicas del conflicto armado en tumaco y su impacto humanitario. Recuperado de http://cdn.ideaspaz.org/media/website/document/52f8ecc452239.pdf 
Freire, P. (1996). Pedagogía de la esperanza. Un reencuentro con la pedagogía del oprimido. Río de Janeiro: Siglo XXI.

Fromm, E. (1968). La revolución de la esperanza. Bogotá: Fondo de Cultura Económica.

Galtung, J. (2016). La violencia estructural y directa. Cuadernos de Estrategia, (183), 147168.

González-Stephan, B. (1994). Escritura y modernización; la domesticación de la barbarie. Revista Iberoamericana, 60, 109-124.

Kvale, S. y Brinkmann, S. (2009). Interviews: learning the craft of qualitative research interviewing. California: Sage.

Londoño, S. (2019). Un camino y múltiples recorridos en la educación para la paz en Colombia. En F. Arrieta, \& G. Boffey, Hacia la reconciliación (págs. 197-212). Madrid: Catarata.

Mignolo, W. (1978). Elementos para una teoría del texto literario. Barcelona: Crítica.

Molano, A. (4 de septiembre de 2003). Diálogo con Alfredo Molano. (Cátedra PúblicaUniversidad de Antioquia, Entrevistador) Universidad de Antioquia.

Moreno, M. A. (2012). La posición del sujeto en el paso a la vida civil; reflexiones a partir de un estudio sociológico. Borromeo, (3), 566-594.

Ramírez, S. R. (2020). Lineamientos para una propuesta educativa critica para escuelas en conflicto armado (tesis doctoral), Universidad de San Buenaventura, Cali.

Salamanca, L. (2007). Entre balas y palabras. Relaciones discursivas en torno al conflicto armado colombiano. Pensamiento Jurídico, 19, 95-118.

Semana. (2 de febrero de 2014). El niño bomba. Recuperado de https://www.semana.com/nacion/articulo/el-nino-bomba/115056-3

Semana. (5 de mayo de 2014). Las FARC usaron 'niños bomba' en Tumaco. Recuperado de https://www.semana.com/nacion/articulo/las-farc-usaron-ninos-bomba-entumaco/387400-3

Unesco. (2011). Una crisis encubierta: conflictos armados y educación. París: Unesco.

Walsh, C. (2003). Geopolíticas del conocimiento y colonialidad del poder; entrevista a Walter Mignolo. Revista Académica Universidad Bolivariana, 1(4), 1-27. 